\title{
Conceptual design for oil palm evacuation to improve ergonomics issues of collecting fresh fruit bunch
}

\begin{abstract}
Oil palm evacuation are still labour dependent and room for mechanisation may still exist. With the importance of this industry as one of nation's economic contribution the efforts are still considered viable. In order to reduce, improve and empower labours a new concept design was developed. A mock-up interaction was done in virtual environment in order to assess the ergonomic aspect of the design in order to determine the pros and cons of the concept design. The findings had led to a conclusion for a requirement of a more thorough assessment to assess human machine interaction in terms of biomechanical effects.
\end{abstract}

Keyword: CAD; Ergonomics; Human machine interaction; Machine design; Oil palm 